\title{
Materials Libraries as Vehicles for Knowledge Transfer
}

\author{
By Sarah Wilkes (University College London)
}

As part of a wider picture of increased funding for interdisciplinary art-science projects, a number of institutions and instruments have arisen in the UK over the last 35 years, which aim to facilitate the transfer of knowledge about materials between materials producers and users. In this paper, I focus on the development of one kind of institution in particular - the materials library. The paper examines the perceived need for the development of these institutions resulting from a paucity of materials education in the arts, a perceived problem of communication between increasingly specialised disciplines and a rapidly increasing number of autonomous and 'imperfectly characterised' new materials. The moral imperative behind materials libraries is also discussed. There is a common belief that the 'correct' or 'incorrect' use of materials can have positive or detrimental effects on society, and materials libraries are seen to be a way of controlling and 'bettering' the development of materials. This paper also examines different and competing modes of knowledge transfer employed in materials libraries, and suggests that we might be seeing a shift in the nature of knowledge communication from a predominantly text-based mode of learning to one emphasising play, experimentation and performance. Finally, the paper critically examines the notion that the transfer of knowledge across perceived boundaries between different kinds of knowledge is a kind of panacea for societal problems.

\section{Introduction}

As a result of the fast pace of innovation in materials science, we have a far greater range of materials available to us than ever before. In 1997, popular science writer Philip Ball estimated that there were between 40,000 to 80,000 materials to choose from when fabricating an artefact. Ball argued that 'this century has seen a shift in the use of materials that is like nothing that has gone before' (1997: 4). Some materials users in the art and design community express the idea that the 'correct' use of materials in design is essential for creating beauty, quality of life and sustainability. However, the overwhelming number of new and unfamiliar materials available today leaves them faced with a huge variety of choices they are ill-equipped to negotiate due to a lack of materials education. Equally, materials producers and material scientists comment that knowledge about materials is not transferred from maker to user and materials needs are not relayed back to manufacturers, as a result of which many materials never find a niche in a competitive marketplace.

There is a common complaint that these obstacles to the burgeoning UK materials industry are caused by a divide between science and arts communities ${ }^{1}$. The origin of this divide lies in a cumulative process of disciplinary specialisation and the fragmentation of knowledge about materials over perceived professional boundaries. I

\footnotetext{
${ }^{1}$ Whilst I recognise that the divide between 'arts' and 'science' communities might be considered merely an arbitrarily enforced border (Latour 1999: 2), these are the terms used by my informants, and as such this anthropological study empathises with their 'common sense' distinction (Miller 2005: 14).
} 
will argue that this divide results in the conception that there exist two kinds of knowledge about materials: one technical, objective, text-based and rational, and one aesthetic, intuitive, material and performative. These are thought to be the domains of two different kinds of people: scientists and artists. This division of knowledge results in communication problems between materials producers and users and is thought to have adverse effects on both the economy and society as a whole, influencing success of materials, satisfaction of consumers, beauty, sustainability, and quality of life.

The solution is commonly believed to be the transfer of knowledge about materials between communities thought of as socially and professionally divided. This paper argues that materials libraries can be seen as part of a larger project encouraging interdisciplinary transfer of knowledge about materials in order to control their development. The artist's role is commonly thought to be that of a visionary whose practice enables them to gain an understanding of the social efficacy of materials. The discourse surrounding the artist's work in materials libraries resonates with the idea that creativity, skill and 'embodied knowledge' reside in the process of working with a material, and can be acquired through physical experience.

\section{Research Context}

This article is based on research that began in May 2008 and continues to the present day. The focus for this research was initially a range of physical materials libraries based in both academic institutions and private professional practices in London, England. I also conducted interviews within materials consultancy services and professional bodies for the materials industry. I am currently conducting AHRCfunded research with my collaborative partners, the Institute of Materials, Minerals and Mining (IOM3). The IOM3 is a professional body that sits on the cusp of the arts and sciences, spans academia, industry and government, and represents both producers and users of materials ${ }^{2}$.

Research was based around participant observation of staff and users of materials libraries and supplemented by interviews with students, designers, artists, materials librarians, materials consultants and material scientists involved in interdisciplinary endeavours. Where possible, interview questions were prompted by specific materials and objects. The insights in this paper were also supported by textual analysis of official governmental documents relating to the materials industry ${ }^{3}$, in addition to less formal reports written by those involved in the work of materials libraries and materials education ${ }^{4}$, and a growing number of books, databases and software tools designed to help the materials-using community choose between the plethora of materials available to them ${ }^{5}$.

\section{Materials Libraries}

A number of new and innovative materials libraries have appeared in the UK over the last 35 years, which are dedicated to collecting, displaying and educating people about

\footnotetext{
${ }^{2}$ In particular through the Materials Knowledge Transfer Network (Materials KTN), which it manages on behalf of the Technology Strategy Board.

${ }^{3}$ DTI 2006; Materials KTN 2006.

${ }^{4}$ Aldersey-Williams 2005; Ward 2008; Miodownik 2009; Byko 2005.

${ }^{5}$ Ashby and Johnson 2002; Beylerian, Dent and Quinn 2007.
} 
materials. The first institutionalised materials library for the arts community in the UK was founded at the Royal College of Art in 1974 for the purpose of educating art, design and architecture students. According to one interlocutor who was involved in the endeavour, the materials samples, brought back from visits to trade fairs by the librarian, were introduced on the basis of popular demand and received by students with a 'hunger that resulted in queues of students' to use the library. Since then, a number of other materials libraries have appeared in London within academic and educational institutions ${ }^{6}$, within private design practices $^{7}$, as government-funded advisory services for the 'materials' and 'creative' industries ${ }^{8}$, and as commercial ventures 9 .

In general, the aim of materials libraries is to ensure that specialist knowledge about materials is not split along the supposed divide between scientists and artists. As a result, these libraries aim to facilitate the creation of personal and professional 'networks' between artists, designers, architects, artisans, material scientists and manufacturers. Materials libraries also source, collect and classify physical samples of materials, ranging from more familiar materials like woods and metals to weird and wonderful substances like NASA-inspired aerogels. These library collections enable both artists and scientists to physically encounter materials and gain an understanding of them. According to one materials librarian, Carol, they act as 'inspirational collections', allowing users to develop a sensitivity to the possibilities and social efficacy of materials.

\section{Specialisation and Fragmentation of Knowledge}

The logic behind the development of the materials library as a space for engagement between science and arts communities is that many material scientists are thought incapable of imagining and fulfilling the needs of materials users. Maine, Probert and Ashby identify a 'mismatch between designers' and entrepreneurs' understanding of market needs...exacerbated by the many layers of separation between material and end consumer' as a factor in the slow uptake of new materials (2004: 16). Materials can take as long as 20 years to reach the marketplace due to 'insufficient knowledge of market applications by inventors' (2004: 16).

Mark Miodownik of the King's College Materials Library has also argued that characteristics such as smell and feel, which contribute to the attractiveness of a material, are ignored by many materials developers. He describes the contemporary climate of materials science as one that is missing out on the 'tactile pleasures of materials' (Byko 2005: 64). Frances, a student and practitioner of industrial design, complained that 'boffins don't want to do the kind of testing of new materials required by designers like me'. Just as James Leach notes in his ethnography of artscience collaborations, scientists are thought to be restricted by 'the very specialisation of their knowledge' in their understanding of the 'cultural' aspects of materials, such as how they will be received and used (Leach 2005: 148).

\footnotetext{
${ }^{6}$ Central St. Martins and London Metropolitan Materials and Products Collections, Kingston University's Rematerialise Creative Resource, Middlesex University Teaching Resources and King's College Materials Library.

${ }^{7}$ ARUP, Heatherwick Studio, Pentagram, Foster + Partners.

${ }^{8}$ Materials Knowledge Transfer Network (Materials KTN) resource centre.

${ }^{9}$ SCIN, Material Lab.
} 
In the view of those behind materials libraries, this is exacerbated by the professional and social distance between materials developers and designers. Miodownik states that 'the scientists, technologists and industrialists involved in the development of new materials move in both academic and social circles widely separated from industrial designers, architects, crafts people and artists' (2006: 2). Jo, an artist and materials librarian, suggested to me that one reason for the development of materials libraries was the need for people and institutions that could 'bridge the communication gap between disciplines', something seen as 'increasingly vital' in the face of a perceived separation of science and art as 'research takes specialists deeper and deeper into their fields - unable to see any overlaps or the bigger picture'. The worry is that the introduction of new materials by an 'isolated materials-science community holds the prospect of a further deepening of the rift between scientists and society' (Miodownik 2009: 3).

This anxiety surrounding the specialisation and isolation of the materials science community is compounded by the lack of materials education received by many designers, architects and artists. Duncan, a materials consultant at an engineering firm, commented that the lack of materials knowledge displayed by many practising architects was a 'perennial problem', since many 'just don't learn much about the practical uses of materials, their properties, how to form them, their limitations'. Jo commented, 'I have even had to explain in the past that stone is not manufactured but quarried from the earth, and that metals are not quarried in sheet or lump form but extracted from ores'.

\section{Communication Problems}

The lack of so-called 'technical' knowledge about materials in the arts community is often expressed in terms of a 'lack of vocabulary' or 'problems of communication'. Artist and materials librarian Jo stated that 'students come in with a problem to solve, but they are limited by their materials vocabulary'. Delegates at a recent Materials in Art and Design Education conference expressed a wish for a 'better understanding of the language of materials to aid selection and specification', and emphasised the 'importance of equipping students with the language and knowledge to interact effectively with materials producers and specify materials in terms they would understand' (Ward 2008: 6). My informants displayed a widespread belief that scientists and artists spoke 'different languages', with an implicit suggestion that this displayed their radically different ways of thinking about the material. Materials scientist and librarian Alex explains, "the problem is that designers will talk to you about "texture", about something that "feels like putty". But you'd never hear a materials scientist describe a material like that. To a materials scientist, that's the surface properties of the material'.

The concern amongst many of my informants is that material scientists and materials users have radically different expectations and understandings of materials. Scientists consider the structural, chemical and electrical properties of materials to be paramount, and the sensual and aesthetic properties as secondary, whereas industrial designers, for example, need materials that 'please users' and 'touch them emotionally in some way' (van Kesteren et al. 2007: 41). 


\section{Materials as Drivers for Social Change}

This article contends that there has been a recent shift in attention towards materials within the UK, with growing recognition of their importance to both economic and environmental sustainability (Materials KTN 2006: 3). For example, the Department of Trade and Industry's (DTI) Materials Innovation and Growth Team assert the 'importance of materials to quality of life and protection of the environment' (2006: 32), and the Foresight Programme asserts that it is about 'preparing for the future...deploying resources in the best way possible - for competitive advantage, for enhanced quality of life and for sustainable development' (DTI Foresight Report 1999). 'Quality of life' and the 'future of society' are phrases used at least once in every single report on the aims of the materials sector that I have read.

Similarly, many in the design community display the notion that the 'correct' use of materials in design is essential for creating beauty, quality of life and 'sustainability'. Mike Ashby and Kara Johnson have co-authored a book intended to aid design students and practitioners in the selection and understanding of the bewildering array of materials available today. According to them, the appropriate use of materials will lead to 'satisfaction and delight' amongst consumers and a long product life for the design, whereas 'unremarkable designs with dull or inappropriate materials are...transitory; we discard them without a thought' (2002: 16). They state that design carries with it the 'heavy responsibility' of inducing emotional attachments in people that result in the well-being of the consumer and preservation of the environment (2002: 63). This implies that the materials choices made by designers not only have economic implications, but also moral and social consequences. There is a sense that the correct use of materials could lead to the creation of wealth, sustainable development and well-being, whereas their incorrect use could lead to disaster ${ }^{10}$. This establishes materials as drivers of social change, with the potential to alter society for better or worse.

\section{Unfamiliar and Autonomous Materials}

Numerous anthropologists, historians of science and popular writers have demonstrated that the reaction to new materials and technologies can often be one of fear or anxiety (Warnock 1985; Edwards 2002), and that Euro-American anxieties often focus on 'where to put limits on technological inventions that promise to run away with all the old categorical divisions' (Strathern 1996: 519). This article argues that innovations in materials are commonly perceived to have an impact on society, and that these developments are increasingly seen as transformative and even 'runaway' (Leach 2005: 141).

There is a sense that whereas designers in the past would have drawn on their personal experiences of materials in order to make decisions about them, the sheer quantity of new materials makes this personal encounter with all available materials problematic. Ashby and Johnson maintain that industrial designers do not have sufficient access to information of the sort they need to understand the 'personality' of a material (Ashby and Johnson 2002: 2); there is little by way of support to help designers determine which materials will 'arouse interest, stimulate and...have a personality that resonates

\footnotetext{
${ }^{10}$ See for example Eric Drexler's apocalyptic predictions for the future of nanotechnology in Engines of Creation (1986).
} 
with the tastes and aspirations' of a user, aside from 'intuition' and trial-and-error (2002: 15).

However, contemporary anxieties around unfamiliar yet abundant materials are not something completely novel. Echoes of this putative crisis can be seen in Gottfried Semper's strikingly similar fear of crisis in the mid-nineteenth century. He claimed that 'the present has no time to become familiar with the half-imposed benefits' of new materials such as rubber and gutta-percha which can be 'vulcanised and utilised in a thousand imitations of wood, metal and stone carving' (Semper cited in Mallgrave 2005: 541). Semper argued that this abundance of new materials 'confused' the industrial and 'higher arts' (ibid). Whereas 'the founders of flourishing art once had their material kneaded beforehand, as it were, by the beelike instinct of the people', the rapid pace of technological innovation in the mid-nineteenth century meant that 'practice receives a material from science ready to process as it chooses, but before its style could have evolved through many centuries of popular usage' (Semper In Mallgrave 2005: 542).

Semper's anxieties resonate with modern-day complaints that the arts community is confronted with materials that already have a function inscribed on them, not by generations of artists or the 'beelike instinct of the people', but by material scientists in laboratories (Semper in Mallgrave 2005: 542). It is not just the arts community that makes choices about what constitutes our material environment. The scientists, engineers and businessmen involved in their manufacture play a part in determining the form, function and 'personality' of materials. Many new materials are designed to change as a result of environmental stimuli, to interact with other materials or to perform some completely new function ${ }^{11}$. For example, smart materials are designed with self-cleaning or conductive qualities already embedded in them. Synthetic skin, blood and bone are designed to heal themselves. These materials are inscribed with a function at the production stage and explode the idea of the artist's materials as raw matter (Küchler 2008: 102). As Sophie, a product designer and materials librarian, commented, 'some of these materials have so much personality that they overshadow the design...most of the nano-tech materials like self cleaning glass and stain resistant fabrics have such a character that they dominate the final product'. This article therefore proposes that materials libraries constitute an 'attempt to take control over the apparently runaway character' of technological innovation (Leach 2005: 143).

\section{Interdisciplinarity and 'Social Knowledge'}

The discourse surrounding materials libraries suggests that artists are 'representatives of different social understandings' of materials, who can help to set straight the course of materials development today (Leach 2005: 148). Industrial designers and artists are often assumed to have intuitive expertise in understanding people's sensual, tactile, aesthetic and emotional needs, and the materials that fit those requirements. Miodownik believes that artists have an understanding of the 'cultural properties' of materials that material scientists lack, as a result of their specialised training. $\mathrm{He}$ argues that the arts community has taken up the task of 'sifting through the wealth of new materials created for performance...to find the ones that match society's cultural

\footnotetext{
${ }^{11}$ This article does not contend that there has been some radical rupture in nature of materials - many of these 'smart', 'new' materials have precedents in far older materials (Küchler 2005,). However, the ways these materials are talked about by both producers and consumers - as 'smart', 'active' and 'functional' materials - perhaps indicates some change in our perception of them.
} 
outlook' (2005: 507). Since it is the materials that they use which 'clothe us...define our homes and cities' (Miodownik 2005: 507) and 'give substance to everything we see and touch' (Ashby \& Johnson 2002: 1), the choices that product designers, fashion designers and architects make are thought to be of immense importance.

Materials libraries play a crucial role in the production of this kind of social knowledge by bringing the arts community into contact with materials technology. A large majority of materials librarians have professional backgrounds in art and design, and when selecting materials for their collections, they rely to a large extent on 'intuition about what can be done with a material' (Sophie, product designer and librarian). Most collections cater primarily to the needs of artists and designers, and explicitly aim to find new and exciting applications for existing materials. One materials librarian at an academic institution commented, 'it is exciting when students use a material for some purpose other than its intended one' (Jo, artist and librarian). Delegates at the Materials KTN Materialise Forum expressed the notion that in order for 'appealing uses' to be found for new materials, designers must be involved: 'All too often, companies jealously guard their new materials as commercial secrets, and so do not find consumer applications for them simply because they have not been shown to the kind of people who could come up with the ideas' (Aldersey-Williams 2005). Both official reports by informants and informal observations from fieldwork support the idea that artists are thought to have privileged access to knowledge of how best to use materials.

\section{Different Modes of Knowledge Production}

One way in which materials libraries facilitate the production of 'social knowledge' about materials is through physical experience of materials. The website of one materials library states that 'generating physical encounters with matter...provides an often forgotten way into...technical knowledge'. The idea that knowledge can be gained through practical engagement with the world is one that harks back to early modern notions of experimental philosophy (Stafford 1994: 281). I contend that some materials libraries are attempting to revive this forgotten notion that touch and experiment provide 'essential...means of acquiring knowledge' (Classen and Howes 2006: 201).

\section{Residual Visualism}

However, materials education is a discipline in flux and the extent to which each of the materials libraries emphasises the importance of play, touch and the senses in the production of knowledge varies. At least two of the materials libraries I encountered grew from collections of architectural catalogues into what they are today, and as such, rely to an extent on text-based modes of communication. Samples and swatches of materials have become a significant, if not the most important, part of these collections. Nonetheless, about two thirds of the collections were taken up with folders of printed information, and written labels mediated visitors' experiences of some samples. In another materials library, 2-D images were used to help the librarian overcome the communication barrier between materials scientists and artists. Alex, a materials scientist and librarian, comments, 'designers come in here a lot, and the problem is that often what's exciting about the material is very complicated'. He explains that the cover sheets of textual and visual information placed in front of the 
materials in the library display are there to 'capture the imagination'. Sophie, a product designer and materials librarian, remarks that she is considering making a photo gallery of the new materials she had been unable to get hold of, as 'many of the materials that designers find exciting are visually stimulating'.

Representation of materials in two dimensions is nothing new in design or architecture, since orthographic drawing has always operated in the two-dimensional realm. However, what is interesting about these observations is that some designers and materials librarians hardly distinguish digital images and photographs from threedimensional materials. The 2-D image is used as a means to 'evoke the attention of the hand and eye', displaying an inclination to think of the material in terms of surfaces or finishes that can be captured on camera (Lloyd Thomas 2007: 5). Whilst the use of these images does allow for the communication of information about materials, I would argue that it also demonstrates the importance of image-based thought for many designers and betrays a notion of the material as a mere surface or the 'look' of an object.

\section{Play, Experimentation and Knowledge Production}

This stands in stark contrast to another materials library, which features no publicly available written information about their materials. One of the librarians describes the conscious choice they made not to include a catalogue or database in the collection: 'If a material comes with a data pack, that just gets filed, but we don't put it on display...we don't want people to be searching through words to find materials they want...you go to the materials first...you should just be standing and playing with materials' (Emma, artist and materials librarian).

Despite a residual valorisation of text-based modes of learning in some materials libraries, all the librarians I spoke to emphasised the importance of touch. One of the basic tenets of all materials libraries seems to be that people can only gain an understanding of certain material properties, such as smell, feel and sound, by 'experiencing the materials directly - touching them, manipulating and interacting with them in different ways' (Miodownik in Ward 2008: 2). Engineer and materials consultant Duncan felt that sensory experience of a material was essential for designers and architects he works with 'to really engage in a thought process of how you use a new material you really have to see it, hear it, feel it, break it...'scratch and sniff' sessions I like to call them'.

Sight and text-based learning have a long history of valorisation within the sciences, but there exists a counter-tradition which values the directness of touch over the distance of sight. Susan Stewart notes that before the Enlightenment, touch was often though to be 'the most important vehicle for our access to reality' (1999: 34), since it directly involves thresholds of subject and object. Stewart argues that 'the act of touching exerts pressure on both toucher and touched and therefore threatens the distinction between self and other' (1999: 6). This emphasis on touch is not, however, intended as a condemnation of 'vision' per se. Vision is thought to play an important part in the work of the materials library in connection with all of the other senses. The sensual experience many materials libraries advocate does not exclude vision, but rather encourages a synaesthesic and processual approach through experimentation and play. There is a sense that with some new materials, this kind of experimental engagement is necessary, since we cannot see what they do by just looking at them or 
touching them. For example, a meta-material is invisible to the naked eye. We cannot manipulate it to get a feel for it nor smell it like we would molten metal. We are sensually disconnected from it. Even with something like a magnetic liquid, 'you can't just see what it does with your eyes or your hands. You have to actually have some equipment... if you take a magnet to it, it turns into a solid' (Miodownik, 2005b).

This idea that physical experience is necessary for a holistic understanding of a material resonates with Barbara Stafford's belief that we are currently seeing a revival of play and experiment in the learning process (1994). She contends that during the eighteenth century, 'ocular, tactile, kinaesthetic and auditory skills' (1994: xxii) were central to the shaping of knowledge, which was as much about pleasure and entertainment as learning; it was both 'creative and playful' (1994: xxv). This was supplanted as an avenue of meaningful communication by text-based modes of communication (1994: xxi), but she asserts that we are beginning to see a return to a form of knowledge that lies between entertainment and information, practice and cognition (1994: 14).

\section{Problems of Access}

The rhetoric surrounding materials libraries sets them up as the solution to problems encountered by the materials and creative industries. However, despite the institutionalisation of materials libraries, many librarians still have difficulties accessing the materials they want. Artist and materials librarian Jo stated that 'materials are becoming harder and harder to get hold of'. According to materials librarian Carol, a large number of designers and architects remain hungry for greater access to new materials, and a greater understanding of the processes by which they are made and manipulated. However, in the eyes of many involved in materials education, concerns over corporate secrecy and ownership on the part of materials producers are a hindrance to both creativity and technological progress. At the Materials in Art and Design Education conference, participants complained that today's relationships between academia and industry were 'not effective'. They felt that 'industry was insufficiently willing to make materials, particularly new materials, available to students for experimentation' as a result of 'budgetary reasons' and 'worries about control of intellectual property' (Ward 2008: 6).

Based on experiences of trying to source materials myself and participant observation in materials libraries, I would argue that this seems to be exacerbated in products that are susceptible to 'reverse engineering'. Materials scientist and librarian Alex explained to me that companies are sometimes loath to donate materials for fear of breaching the patent: 'For example, we recently dealt with a manufacturer who sourced their materials from a materials company...the manufacturers were willing to give us the product, but the materials company wouldn't allow it'. They bought the product. Using 'materials expertise' and information in the public domain, Alex was able to work out what the product was and how it was made. This resonates with Susanne Küchler's argument that some materials are much harder to 'domesticate' than others, and 'thus are not readily possessed by corporate institutions in the same way as earlier machine-generated prototypes were' (Küchler 2008: 105). Knowledge is thought to be inherent in some materials and cannot always be controlled by manufacturers, despite their best efforts. 
Within the materials industry, the circulation of materials and knowledge about them is actively promoted one minute and tied down the next ${ }^{12}$. This paper argues that problems of access to materials encountered by librarians suggest that both the development of materials libraries and the obstacles caused by corporate secrecy and copyright both stem from the same desire to control materials that are increasingly thought of as autonomous from their makers and users. This deserves attention, as it begins to explore the fallibility of interdisciplinary endeavours, which are often seen uncritically as a panacea for contemporary society.

\section{Conclusion}

The aim of materials libraries, executed with mixed success, is to share knowledge by transferring it between communities that are thought of as socially and professionally divided. The fact that each materials library encapsulates slightly different combinations of text and performance-based communication allows for a comparison of modes of knowledge transfer. Whereas text-based learning has been the dominant mode of knowledge transfer since the mid-eighteenth century, my research suggests that we are starting to see a change in the nature of knowledge communication within materials education. I would suggest that we find ourselves, as Stafford (1994) has argued, mid-way between a largely text-based mode of learning and knowing and one that emphasises play and experimentation. It is hard to speculate where this will lead in the future. Some of my informants' actions suggest that we might see a return to text or image-based knowledge transfer. For example, some seemed keen to set up digital archives of materials, or encouraged 'more material data sheets' (Tim). Others, by contrast, emphasise the importance of theatricality and performance in the future of materials education. For example, the King's Materials Library events are theatrical, magical and about the revelation of mystery through performance. They describe their work as 'curiosity led'. Miodownik explicitly relates his endeavour to that of entertaining, yet instructive, early modern cabinets of curiosity, describing his collection as a 'cabinet of wonder'. These competing ideas about how knowledge is most effectively transferred are not only interesting anthropologically, but have important implications for pedagogic theory and knowledge production within the arts and sciences.

\section{About the author}

Sarah Wilkes is a PhD candidate in Material and Visual Anthropology at University College London and is currently doing AHRC-funded research, in collaboration with the Institute of Materials, Minerals and Mining, into how notions of sustainability impact on the ways materials users interpret, make judgements about, specify and use materials in the UK today. She can be contacted at s.wilkes@ucl.ac.uk

\footnotetext{
${ }^{12}$ As I have discussed elsewhere (Wilkes 2008), there exists a hierarchy of materials and institutions within the materials community; some materials are harder to obtain than others, and some institutions find it much easier to get hold of samples than others. Just as with the kula, at one end of the continuum, the exchange of materials is an open system in which most players can participate, but the other end is tightly controlled, and movements of materials become the 'objectification of hierarchical difference' (Weiner 1994: 397).
} 


\section{Bibliography}

Ashby, M and Johnson, K. (2002), Materials and Design: The Art and Science of Material Selection in Product Design, Butterworth Heinemann.

Ball, P. (1997), Made to Measure: New Materials for the 21st Century, Princeton University Press.

Beylerian, G, Dent, A and Quinn, B. (2007), Ultra Materials: How Materials Innovation is Changing the World, Thames and Hudson.

Byko, M. (2005), Materials Library: Exploring the Tactile Pleasures of Materials, JOM 57(6): 64.

Classen, C and Howes, D. (2006), 'The Museum as Sensescape: Western Sensibilities and Indigenous Artifacts', in E. Edwards, C. Gosden, and R. Philips (eds), Sensible Objects, Oxford, Berg.

Department of Trade and Industry Foresight Report, (1999), Tomorrow's Materials, available at: www.foresight.gov.uk/Materials/Tomorrows_Materials_June_1999.pdf

Department of Trade and Industry Materials Innovation and Growth Team, (2006), A Strategy for Materials, available at: http://www.innovateuk.org/_assets/pdf/corporatepublications/dti_a\%20strategy $\% 20$ for $\% 20$ materials.pdf

Drexler, K.E. (1986), Engines of Creation, Anchor Press.

Edwards, J. (2002), 'Bits and Bytes of Information', in N. Rapport (ed), British subjects: An Anthropology of Britain, Berg.

Küchler, S. (2008), Technological Materiality: Beyond the Dualist Paradigm, TCS 25(1): 101-121.

Kwint, M, Breward, C and Aynsley, J (eds), (1999), Material Memories: Design and Evocation, Berg.

Leach, J, (2005), 'Being In Between: Art-science collaborations and a Technological Culture', Social Analysis, 1: 141-160.

Leach, J. (2007), 'Differentiation and Encompassment', in A. Henare, M. Holbraad, and S. Wastell (eds), Thinking Through Things, Routledge.

Lloyd Thomas, K. (2007), Material Matters: Architecture and Material Practice, London, Routledge.

Maine, E, Probert, D and Ashby, M. (2004), Investing in New Materials: a Tool for Technology Managers, Technovation 25: 15-23.

Mallgrave, H. (2005), Modern Architectural Theory: A Historical Survey, 1673-1968, Cambridge University Press.

Materials Knowledge Transfer Network (Materials KTN) (2006), Focus Newsletter, Issue 1: April/May.

Miodownik, M. (2005), 'Facts not opinions?' Nature Materials, 4: 506-508.

Miodownik, M, (2005b), [audio] BBC Radio 4's The Material World: One Man's

Materials. 10/02/2005, available at:

http://www.bbc.co.uk/radio4/science/thematerialworld_20050210.shtml 
Miodownik, M. (2006), EngineeringArt EPSRC Grant Application, available at: http://gow.epsrc.ac.uk/ViewGrant.aspx?GrantRef=GR/T21257/01

Miodownik, M. (2009), Materials for the Creative Industries Report. Materials UK for the House of Lords, available at: http://www.matuk.co.uk/docs/MaterialsUKCreativeIndustries.pdf

Stafford, B. (1994), Artful Science: Enlightenment Entertainment and the Eclipse of Visual Education, MIT Press.

Stewart, S. (1999), Prologue: From the Museum of Touch. In Material Memories: Design and Evocation, Kwint, M, Breward, C and Aynsley, J. (eds), Berg.

Strathern, M., (1996), 'Cutting the Network', Journal of the Royal Anthropological Institute, 2 (3): 517-535.

Van Kesteren, I, Stappers, P and de Buijn, C. (2007), Materials in Product Selection. International Journal of Design, 1(3): 41-55.

Ward, J. (2008), Materials in Art and Design Education, available at: www.iom3.org/fileproxy/37527

Warnock, M. (1985), A Question of Life: the Warnock Report on Human Fertilisation and Embryology, Oxford: Blackwell.

Weiner, A. (1994), 'Cultural Difference and the Density of Objects', American Ethnologist, 21(2): 391-403.

Wilkes, S. (2008), Materials Matter: An Anthropological Study of Materials Libraries, Unpublished MA Dissertation, University College London. 